\section{Predicting the Risk of Radiation Pneumonitis and Pulmonary Function Changes after Breast Cancer Radiotherapy}

\author{
Parinaz Mehnati ${ }^{1 \oplus}$, Maryam Ghorbanipoor ${ }^{2 *}$, Mohammad \\ Mohammadzadeh³, Behnam Nasiri Motlagh³, Asghar Mesbahi4
}

\begin{abstract}
Background: Radiotherapy plays an important role in the treatment of breast cancer. In the process of radiotherapy, the underling lung tissue receives higher doses from treatment field, which led to incidence of radiation pneumonitis.

Objective: The present study aims to evaluate the predictive factors of radiation pneumonitis and related changes in pulmonary function after 3D-conformal radiotherapy of breast cancer.

Material and Methods: In prospective basis study, thirty-two patients with breast cancer who received radiotherapy after surgery, were followed up to 6 months. Respiratory symptoms, lung radiologic changes and pulmonary function were evaluated. Radiation pneumonitis (RP) was graded according to common terminology criteria for adverse events (CTCAE) version 3.0. Dose-volume parameters, which included percentage of lung volume receiving dose of $\mathrm{d} G \mathrm{G}\left(\mathrm{V}_{5}-\mathrm{V}_{50}\right)$ and mean lung dose (MLD), were evaluated for RP prediction. Pulmonary function evaluated by spirometry test and changes of FEV1 and FVC parameters.
\end{abstract}

Results: Eight patients developed RP. Among the dose-volume parameters, $\mathrm{V}_{10}$ was associated to RP incidence. When $\mathrm{V}_{10}<40 \%$ and $\mathrm{V}_{10} \geq 40 \%$ the incidences of RP were $5.26 \%$ and $61.54 \%$, respectively. The FEV1 and FVC had a reduction 3 and 6 months after radiotherapy, while only FEV1 showed significant reduction. The FEV1 had more reduction in the patients who developed RP than patients without RP ( $15.25 \pm 3.81$ vs. $9.2 \pm 0.93)$.

Conclusion: Pulmonary function parameters, especially FEV1, significantly decreased at 3 and 6 months after radiotherapy. Since most patients with breast cancer who developed RP did not show obvious clinical symptoms, so spirometry test is beneficial to identify patients with risk of radiation pneumonitis.

Citation: Mehnati P, Ghorbanipoor M, Mohammadzadeh M, Nasiri Motlagh B, Mesbahi A. Predicting the Risk of Radiation Pneumonitis and Pulmonary Function Changes after Breast Cancer Radiotherapy. J Biomed Phys Eng. 2021;11(4):459-464. doi: 10.31661/jbpe.v0i0.1079.

Keywords

Breast Cancer; Radiation Pneumonitis; 3-D Conformal Radiotherapy; Spirometry; Lung

\section{Introduction}

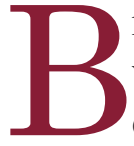
reast cancer is the most common malignant disease in Iranian women with 6160 new cases each year and 1063 cases lead to death [1-3]. Radiotherapy (RT) plays an important role in the treatment of breast cancer as a post-operative modality increasing locoregional control and survival rate $[4,5]$. Radiotherapy of breast cancer typically included two tangential opposed fields to cover chest wall or
${ }^{1} \mathrm{PhD}$, Immunology re-

search center, School of

Medicine, Tabriz Univer-

sity of Medical Sciences,

Tabriz, Iran

${ }^{2} \mathrm{MSc}$, Department of

Medical Physics, School

of Medicine, Tabriz

University of Medical Sci-

ences, Tabriz, Iran

${ }^{3} \mathrm{MD}$, Department of

Radiology, Emam Reza

Hospital, Tabriz Univer-

sity of Medical Sciences,

Tabriz, Iran

${ }^{4}$ PhD, Medical Radia-

tion Sciences Research

team, Department of

Medical Physics, School

of Medicine, Tabriz, Iran

*Corresponding author: Maryam Ghorbanipoor

Department of Medi-

cal Physics, School of

Medicine, Tabriz Univer-

sity of Medical Sciences,

University Main St, East

Azerbaijan, Tabriz, Iran,

postal cod: 16666-

14766

E-mail: a.ghorbanipoor@ gmail.com

Received: 10 December 2018 Accepted: 29 December 2018 
breast tissue. Because of the adjacency of lung to breast tissue, the lung inevitably receives higher doses from treatment field; this lead to incidence of lung injury after radiotherapy [6]. One of the most common radiation-induced lung injuries is radiation pneumonitis (RP) developing 3 to 6 months after radiotherapy. RP is an inflammatory reaction in alveolar region of lung that in severe cases decreases patient quality of life and can be fatal [7]. Symptoms of RP included dry cough, chest pain and lowlevel fever. This complication can be detected by radiological and pulmonary function changes after radiotherapy [8]. Many clinical factors such as age [9], smoking history [10], chemotherapy [11] are associated with RP risk. In addition, three-dimensional (3D) treatment planning systems provides the data of dose distribution and irradiated volume in the organ of interest. Many studies reported that the irradiated lung volume, total dose and dose per fraction influence the risk of RP $[12,13]$.

The present study aims to investigate predictive factors of RP incidence and pulmonary function changes after breast cancer radiotherapy to manifest how pulmonary function changes can predict the risk of radiation pneumonitis.

\section{Material and Methods}

Forty women, who were referred for adjuvant RT after surgery to Imam Reza hospital, Tabriz, Iran, were recruited to this prospective basis study. The ethics committee of Tabriz University of medical sciences approved the study and informed consent was obtained from each patient included in the study. Two patients were omitted from the study because early metastasis and incomplete RT treatment and 6 patients refused to continue follow-ups. The remaining 32 patients were followed up to 6 months after RT. Most of the patients underwent modified radical mastectomy (MRM), and all patients had pathology of invasive ductal carcinoma and received 6-8 cycles of chemotherapy concluded 3-4 weeks before
RT. 30 patients received nodal irradiation to supraclavicular and axillary region.

\section{Treatment technique}

All patients were placed in supine position, with the arms elevated above the head, during the CT simulation and treatment. Two tangential opposed fields were used to cover chest wall and breast tissue in patients who underwent MRM and breast conserving surgery (BCS), respectively. In the patients with possibility of lymph node metastasis, one anterior photon field (with 10-12 degree angel) was used to cover axillary lymph node and supraclavicular fossa. An additional electron beam (6-9 MeV) as a boost to surgical scar was delivered in patients who had undergone BCS. Radiotherapy was delivered with total dose of $50 \mathrm{~Gy}$ in 25 fractions (5 days per week).

Chemotherapy regimen included Adriamycin $\left(60 \mathrm{mg} / \mathrm{m}^{2}\right)$, cyclophosphamide (500-600 $\left.\mathrm{mg} / \mathrm{m}^{2}\right)$ and taxol or taxotere $\left(75 \mathrm{mg} / \mathrm{m}^{2}\right)$.

All patients received 3D-conformal RT with multileaf collimator to reduce lung and heart volume in the treatment field. The dose-volume parameters of mean lung dose (MLD), lung volume, percentage of lung volume receiving at least dose of 5-50Gy $\left(\mathrm{V}_{5}-\mathrm{V}_{50}\right)$ were derived from dose-volume histogram.

\section{Pulmonary function evaluation}

The spirometry tests were obtained before, 3 and 6 months after RT. Two important factors measured by spirometry are Forced vital capacity (FVC) measuring lung volume and Forced expiratory volume in 1 second (FEV1) revealing the properties of large and medium size airways [14]. Changes of these parameters were recorded as the difference between preand post-RT values relative to pre-RT values.

\section{Radiation pneumonitis}

All patients were followed up to 6 months after RT for clinical examination and assessment of respiratory symptoms. Patients underwent computed tomography (CT) scan 4 months 
Pulmonary Function after Breast Cancer RT

after RT. The common radiographic features in the irradiated lung included ground-glass opacities and airspace consolidation. RP was graded based on common terminology criteria for adverse events version 3 (CTCAE v3.0.). The grade 1 is asymptomatic with only radiographic findings, and grade 2 is symptomatic, but not interfering with activities of daily living (ADL). Grade 3 is symptomatic and interfering with $\mathrm{ADL}$ and $\mathrm{O}_{2}$ indicated; in addition to, grade 4 is life-threatening with ventilator support indicated, while grade 5 is equal to death [15].

\section{Statistical analysis}

Paired t-test used to compare spirometry parameters before and after RT. The correlation between RP and spirometry changes was evaluated by independent t-test. Univariate and multivariate regressions methods were used to analyze correlation between RP and dose-volume factors. All the statistical analysis were performed by Stata version 14.2 (StataCrop, Texas).

\section{Results}

Patients and related factors of treatment are shown in Table 1. Eight patients developed grade 1 and 2 RP. There were no severe cases (grade $\geq 3$ ) in this study. From 8 patients, who developed RP, only one patient showed clinical symptom of dry cough, but in the other patients, the grade1 of RP was defined by radiographic features. The area of consolidation and opacities was seen on CT. Sometimes features of atelectasis and ipsilateral pleural effusion were observed.

According to results of univariate analysis, all the dose-volume parameters correlated to $\mathrm{RP}$ incidence, except $\mathrm{V}_{45}$ and MLD. None of patient and treatment-related factors correlated to RP incidence. The results of univariate analysis about the associated factors to RP are summarized in Table 2.

To multivariate analysis, the parameters which highly correlated to each other (cor-
Table 1: Patients and treatment related factors

\begin{tabular}{|c|c|}
\hline Factors & Patient Number (\%) \\
\hline \multicolumn{2}{|c|}{ Gender } \\
\hline female & 32 \\
\hline \multicolumn{2}{|c|}{ Age } \\
\hline Average(range) & $49.37(28-77)$ \\
\hline \multicolumn{2}{|c|}{ Tumor location } \\
\hline right & $15(46.88)$ \\
\hline left & $17(53.12)$ \\
\hline \multicolumn{2}{|c|}{ Surgery } \\
\hline BCS & $12(37.5)$ \\
\hline MRM & $20(62.5)$ \\
\hline \multicolumn{2}{|c|}{ MLD(Gy) } \\
\hline mean \pm SD & $10.76 \pm 3.11$ \\
\hline \multicolumn{2}{|c|}{ Mean lung volume(cc) } \\
\hline mean \pm SD & $2807 / 80 \pm 526.48$ \\
\hline \multicolumn{2}{|c|}{ Mean FEV1 before RT } \\
\hline mean \pm SD & $108.28 \pm 20.23$ \\
\hline \multicolumn{2}{|c|}{ Mean FVC before RT } \\
\hline mean \pm SD & $105.75 \pm 19.03$ \\
\hline
\end{tabular}

BCS: breast conserving surgery, MRM: modified radical mastectomy MLD: mean lung dose, FEV1: Forced expiratory volume in 1 second, FVC: Forced vital capacity, RT: Radiotherapy

relation $>0.85$ ) were omitted from analysis. Among the dose-volume parameters, only the $\mathrm{V}_{10}$ significantly was associated to RP incidence $(\mathrm{P}<0.05)$. The mean value of $\mathrm{V}_{10}$ was higher in patients who developed RP $(44.03 \%$ vs. $35.75 \%, \mathrm{P}<0.0001)$. For $\mathrm{V}_{10}<40 \%$ and $\mathrm{V}_{10} \geq 40 \%$, the RP incidence were $5.26 \%$ and $61.54 \%$, respectively.

Spirometry parameters at 3 and 6 months after RT were compared with pre-RT value and mean relative changes of FEV1 and FVC were compared between two groups with and without RP. The mean values of FEV1 reduction were significantly higher in the group with $\mathrm{RP}$ at 3 and 6 months. Figure 1 illustrated the changes of FEV1 and FVC at 3 and 6 months after RT. The mean relative decrease of FEV1 and FVC in the patients group who developed $\mathrm{RP}$ was $15.25 \pm 3.81,9.97 \pm 2.52$ at 3 months and $15.26 \pm 2.37,12.25 \pm 2.35$ at 6 months after RT. Both parameters of FEV1 and FVC 
Table 2: Results of univariate analysis about the patient, treatment-related factors and dose-volume parameters for association with radiation pneumonitis.

\begin{tabular}{ccc} 
Factors & P-value & Hazard ratio (95\% Cl) \\
\hline gender & 0.494 & $1.036(0.394-2.728)$ \\
\hline age & 0.212 & $1.042(0.976-1.111)$ \\
\hline $\begin{array}{c}\text { Tumor loca- } \\
\text { tion }\end{array}$ & 0.566 & $0.657(0.156-2.760)$ \\
\hline grade & 0.897 & $1.070(0.383-2.986)$ \\
\hline stage & 0.353 & $1.941(0.478-7.881)$ \\
\hline $\begin{array}{c}\text { Surgery } \\
\text { type }\end{array}$ & 0.292 & $0.429(0.089-2.070)$ \\
\hline${ }^{*} \mathrm{MLD}$ & 0.067 & $1.226(0.986-1.524)$ \\
\hline $\begin{array}{c}\text { Lung } \\
\text { volume }\end{array}$ & 0.010 & $0.997(0.994-0.999)$ \\
\hline${ }^{* *} \mathrm{~V}_{5}$ & 0.001 & $1.129(1.052-1.213)$ \\
\hline $\mathrm{V}_{10}$ & 0.002 & $1.265(1.092-1.464)$ \\
\hline $\mathrm{V}_{15}$ & 0.002 & $1.258(1.089-1.454)$ \\
\hline $\mathrm{V}_{20}$ & 0.003 & $1.220(1.071-1.315)$ \\
\hline $\mathrm{V}_{25}$ & 0.003 & $1.212(1.065-1.378)$ \\
\hline $\mathrm{V}_{30}$ & 0.005 & $1.197(1.054-1.360)$ \\
\hline $\mathrm{V}_{35}$ & 0.011 & $1.170(1.037-1.327)$ \\
\hline $\mathrm{V}_{40}$ & 0.012 & $1.158(1.033-1.299)$ \\
\hline $\mathrm{V}_{45}$ & 0.145 & $1.066(0.978-1.162)$ \\
\hline $\mathrm{V}_{50}$ & 0.022 & $1.109(1.014-1.212)$ \\
$*$ MLD: Mean lung dose, ${ }^{*} \mathrm{~V}_{5} \mathrm{~V}_{50}:$ & percentage of lung volume \\
receiving at least dose of $5-50 \mathrm{~Gy}$ &
\end{tabular}

had a reduction 3 and 6 months after RT but FVC changes were not significantly associated to RP incidence.

None of the patient and treatment related factors were associated to pulmonary function reduction at 3 and 6 months after RT. The correlation analysis did not show any relation between dose-volume parameters and FEV1 and FVC reduction after RT.

\section{Discussion}

Radiation pneumonitis is one of the most common adverse effects after thoracic radio-
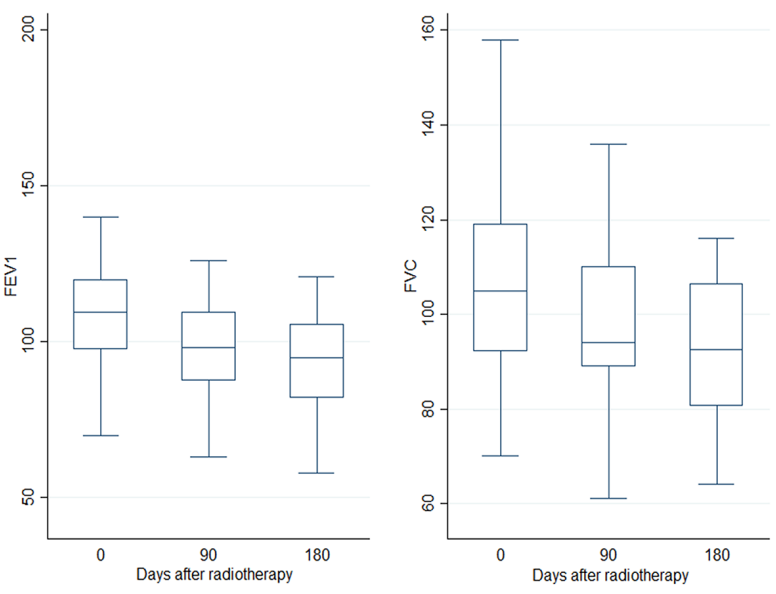

Figure 1: Changes of Spirometry parameters (Forced expiratory volume in 1 (FEV1) and Forced vital capacity (FVC) ) over time; the left graph shows changes of FEV1, 90 and 180 days after radiotherapy in comparison to before radiotherapy (day 0). The right graph shows changes of FVC, 90 and 180 days after radiotherapy in comparison to before radiotherapy (day 0). FEV1: forced expiatory volume in 1 second, FVC: forced vital capacity.

therapy [16]. Identifying patients at risk of $\mathrm{RP}$ is important to modify treatment plan and minimize volume and dose received by lung. Since 3-D conformal RT and multileaf collimation reduces lung volume in the treatment field, no severe cases of RP was seen in this study.

Several clinical and dose-volume factors (MLD, percentage of lung volume receiving at least dose of d Gy) suggested as predictive parameters for RP, but the results are inconsistent. Zhou et al. evaluated predictors of radiation induced lung injury (RILI) in 109 patients with breast cancer who underwent intensity modulated radiation therapy (IMRT). They found that the parameters of age, clinical staging and operation has no effect on RILI incidence and suggested the $\mathrm{V}_{20}$ (threshold value: $29.03 \%$ ) as an independent predictor for RILI [17]. Lee et al. also reported the ipsilateral $\mathrm{V}_{20}$, age and low BMI as predictors of RP in breast cancer patients who underwent hybrid-IMRT 
[18]. In the present study, the $\mathrm{V}_{20}$ was eliminated from multivariate analysis due to high correlation with other dose-volume parameters. The clinical factors did not show any correlation to RP incidence; it can be related to small sample size in this study. From all dose-volume parameters, the $\mathrm{V}_{10}$ statistically was associated to RP. The RP incidence in the group with $\mathrm{V}_{10}<40 \%$ and $\mathrm{V}_{10} \geq 40 \%$ were $5.26 \%$ and $61.54 \%$, respectively. Our results are in agreement with study of Shi et al. which found that $\mathrm{V}_{10}>50 \%$ was associated to severe acute RP in lung cancer patients treated with concurrent chemotherapy and IMRT [19].

The pulmonary function parameters showed significant reductions after radiotherapy, especially in the patients who developed grade 1 and 2 radiation pneumonitis. Decrease in FEV1 and FVC 3 to 6 months after RT represents early inflammatory reaction in the alveolar region known as radiation pneumonitis. Our results are in agreement with other studies that assessed changes of pulmonary function after RT. Spyropoulou et al evaluated pulmonary function changes, 3 months after breast cancer radiotherapy. They found the significant reduction in pulmonary function only in the patients group who received locoregional radiotherapy and chemotherapy [14]. Because the most patients in this study received supraclavicular field, we could not compare FEV1 and FVC changes in the two patients group with and without loco-regional RT. Erven et al. evaluated changes of pulmonary function, $3,6,12$ months and 8 to 10 years in 75 patients with breast cancer who received locoregional RT. They reported that all the pulmonary function parameters significantly had reduction 3 and 6 months after RT and late reduction of parameters were clinically significant in the patients with lower baseline lung function. In addition, they found that the patients with right breast cancer showed more reduced FEV1, 8 to 10 years after RT because the left lung volume is smaller due to heart, while larger lung volume is irradiated in right breast cancer [20].
In the present study, most incidence of RP was seen in the patients with lower pre-RT values of FEV1 and FVC. Nevertheless, there was no difference in pulmonary function reduction in the right and left breast cancer.

Park et al. evaluated predictive factors of RP and pulmonary function changes after definitive concurrent chemoradiotherapy for nonsmall cell lung cancer; they found all parameters of the pulmonary function had reduction after RT and the magnitude of changes was associated to dose-volume parameters. In the patients with grade $\geq 2 \mathrm{RP}$, mean relative reduction of $15.7 \%$ and $9.7 \%$ for FEV1 and FVC at 3 months and $17.9 \%$ and $4.6 \%$ at 6 months were observed. The MLD was associated to FEV1 and FVC reduction at 6 and 12 months after RT. The parameters of $\mathrm{V}_{20}$ and $\mathrm{V}_{30}$ were associated to FEV1 reduction at 6 months and FVC reduction at 12 months [21]. While, in the present study none of dose-volume parameters correlated to pulmonary function changes after RT (only $\mathrm{V}_{10}$ and $\mathrm{V}_{15}$ showed trend, $\mathrm{P}=0.06$ ).

\section{Conclusion}

In the breast cancer patients, pulmonary function parameters especially FEV1 decreased at 3 and 6 months after RT, while most of these patients did not show obvious clinical symptoms. Therefor in the breast cancer, $3 \mathrm{D}$-conformal radiotherapy spirometry test is valuable to identify patients at the risk of radiation pneumonitis.

\section{Acknowledgment}

This work was supported by the office of the vice president for research at the Tabriz University of Medical Sciences in Iran.

\section{Conflict of Interest}

None

\section{References}

1. Emami RS, Aghajani $H$, Haghazali M, Nadali $F$, et al. The most common cancers in Iranian women. Iranian J Publ Health. 2009;38:109-12. 
2. Alizadeh $\mathrm{OH}$, Hoseini $M$, Mirmalek $A$, Ahmari $H$, Arab F, Mohtasham AN. Breast Sarcoma: a review article. Iranian Journal of Surgery. 2014;22:1-11.

3. Mousavi SM, Montazeri A, Mohagheghi MA, Jarrahi AM, Harirchi I, Najafi M, et al. Breast cancer in Iran: an epidemiological review. Breast J. 2007; 13:38391. doi: 10.1111/j.1524-4741.2007.00446.x. PubMed PMID: 17593043.

4. Huang EH, Tucker SL, Strom EA, McNeese MD, et al. Postmastectomy radiation improves local-regional control and survival for selected patients with locally advanced breast cancer treated with neoadjuvant chemotherapy and mastectomy. J Clin Oncol. 2004;22:4691-9. doi: 10.1200/JC0.2004.11.129. PubMed PMID: 15570071.

5. Group EBCTC. Effect of radiotherapy after breastconserving surgery on 10-year recurrence and 15year breast cancer death: meta-analysis of individual patient data for 10801 women in 17 randomised trials. Lancet. 2011;378:1707-16.

6. Madani I, De Ruyck K, Goeminne $\mathrm{H}$, et al. Predicting risk of radiation-induced lung injury. $J$ Thorac Oncol. 2007;2:864-74. doi: 10.1097/ JT0.0b013e318145b2c6. PubMed PMID: 17805067.

7. Mehta V. Radiation pneumonitis and pulmonary fibrosis in non-small-cell lung cancer: pulmonary function, prediction, and prevention. Int $J$ Radiat Oncol Biol Phys. 2005;63:5-24. doi: 10.1016/j. ijrobp.2005.03.047. PubMed PMID: 15963660.

8. Marks LB, Bentzen SM, Deasy J0, Kong FM, et al. Radiation dose-volume effects in the lung. Int $J$ Radiat Oncol Biol Phys. 2010;76:S70-6. doi: 10.1016/j. ijrobp.2009.06.091. PubMed PMID: 20171521. PubMed PMCID: PMC3576042.

9. Lind PA, Wennberg B, Gagliardi G, Fornander T. Pulmonary complications following different radiotherapy techniques for breast cancer, and the association to irradiated lung volume and dose. Breast Cancer Res Treat. 2001;68:199-210. doi: 10.1023/a:1012292019599. PubMed PMID: 11727957.

10. Jin H, Tucker SL, Liu HH, Wei X, Yom SS, Wang S, et al. Dose-volume thresholds and smoking status for the risk of treatment-related pneumonitis in inoperable non-small cell lung cancer treated with definitive radiotherapy. Radiother Oncol. 2009;91:42732. doi: 10.1016/j.radonc.2008.09.009. PubMed PMID: 18937989. PubMed PMCID: PMC5555233.

11. Dang J, Li G, Zang S, Zhang S, Yao L. Risk and predictors for early radiation pneumonitis in patients with stage III non-small cell lung cancer treated with concurrent or sequential chemoradiotherapy. Radiat Oncol. 2014;9:172. doi: 10.1186/1748717X-9-172. PubMed PMID: 25074618. PubMed PMCID: PMC4120001.

12. Roach 3rd M, Gandara DR, Yuo HS, et al. Radiation pneumonitis following combined modality therapy for lung cancer: analysis of prognostic fac- tors. J Clin Oncol. 1995;13:2606-12. doi: 10.1200/ JC0.1995.13.10.2606. PubMed PMID: 7595714.

13. Tsujino K, Hirota S, Endo M, Obayashi K, et al. Predictive value of dose-volume histogram parameters for predicting radiation pneumonitis after concurrent chemoradiation for lung cancer. Int $J$ Radiat Oncol Biol Phys. 2003;55:110-5. doi: 10.1016/s03603016(02)03807-5. PubMed PMID: 12504042.

14. Spyropoulou D, Leotsinidis M, Tsiamita M, et al. Pulmonary function testing in women with breast cancer treated with radiotherapy and chemotherapy. In Vivo. 2009;23:867-71. PubMed PMID: 19779125.

15. Trotti A, Colevas AD, Setser A, et al. CTCAE v3. 0: development of a comprehensive grading system for the adverse effects of cancer treatment. Semin Radiat Oncol. 2003;13:176-81. doi: 10.1016/s10534296(03)00031-6.

16. Wang S, Liao Z, Wei X, Liu HH, et al. Analysis of clinical and dosimetric factors associated with treatment-related pneumonitis (TRP) in patients with non-small-cell lung cancer (NSCLC) treated with concurrent chemotherapy and three-dimensional conformal radiotherapy (3D-CRT). Int J Radiat Oncol Biol Phys. 2006;66:1399-407. doi: 10.1016/j. ijrobp.2006.07.1337. PubMed PMID: 16997503.

17. Zhou ZR, Han Q, Liang SX, et al. Dosimetric factors and Lyman normal-tissue complication modelling analysis for predicting radiation-induced lung injury in postoperative breast cancer radiotherapy: a prospective study. Oncotarget. 2017;8:33855-63. doi: 10.18632/oncotarget.12979. PubMed PMID: 27806340. PubMed PMCID: PMC5464917.

18. Lee TF, Chao PJ, Chang L, et al. Developing Multivariable Normal Tissue Complication Probability Model to Predict the Incidence of Symptomatic Radiation Pneumonitis among Breast Cancer Patients. PLoS One. 2015;10:e0131736. doi: 10.1371/ journal.pone.0131736. PubMed PMID: 26147496. PubMed PMCID: PMC4492617.

19. Shi A, Zhu G, Wu H, Yu R, et al. Analysis of clinical and dosimetric factors associated with severe acute radiation pneumonitis in patients with locally advanced non-small cell lung cancer treated with concurrent chemotherapy and intensitymodulated radiotherapy. Radiat Oncol. 2010;5:35. doi: 10.1186/1748-717X-5-35. PubMed PMID: 20462424. PubMed PMCID: PMC2883984.

20. Erven K, Weltens C, Nackaerts K, et al. Changes in pulmonary function up to 10 years after locoregional breast irradiation. Int $J$ Radiat Oncol Biol Phys. 2012;82:701-7. doi: 10.1016/j.jijobp.2010.12.058. PubMed PMID: 21398052.

21. Park YH, Kim JS. Predictors of radiation pneumonitis and pulmonary function changes after concurrent chemoradiotherapy of non-small cell lung cancer. Radiat Oncol J. 2013;31:34-40. doi: 10.3857/ roj.2013.31.1.34. PubMed PMID: 23620867. PubMed PMCID: PMC3633229. 